\title{
Early Results of Fissurectomy and Advancement Flap for Resistant Chronic Anal Fissure without Hypertonia of the Internal Anal Sphincter
}

\author{
ROSAlia PATTi, M.D., Ph.D., FAUSTO FAMÀ, M.D., Ph.D., ANTONINO TORNAMBÈ, M.D., \\ MARGHERITA RESTIVO, M.D., GAETANO DI VITA, M.D.
}

\begin{abstract}
From the Department of Surgical and Oncological Science, Division of General Surgery, University of Palermo, Palermo, Italy
\end{abstract}

\begin{abstract}
The aim of this study was to assess the efficacy of fissurectomy with skin advancement flap in healing chronic anal fissures without hypertonia of the internal anal sphincter. Twenty-six consecutive patients who failed healing after well-practiced topical medical therapy were enrolled. Anorectal manometry was performed preoperative and 6 months postoperatively. All patients were treated with fissurectomy and advancement flap through healthy skin tissue. All patients healed completely within 30 days from operation. The intensity and the duration of pain postdefecation was reduced significantly with respect to the preoperative values starting from the first defecation. One patient suffered urinary retention, two patients suffered infections, and two partial breakdowns were recorded. At 6 months the maximum resting pressure values were similar to those were detected preoperatively. One month after surgery, anal incontinence was reported in seven patients, four of whom complained about it preoperatively. At 12 months, only three subjects reported incontinence. No patients needed reoperation and no recurrences were detected. The fissurectomy, in combination with advancement flap, is a safe sphincter-saving procedure for the treatment of chronic anal fissures without hypertonia of internal anal sphincter that fails medical conservative treatment.
\end{abstract}

$\mathrm{T}$ HE PATHOPHYSIOLOGY IN the development of chronic anal fissures (CAF) is thought to be a combination of trauma to the anal mucosa, internal anal sphincter (IAS) hypertonia, and poor vascularization. ${ }^{1}$ Most current medical and surgical therapies aim to reduce the maximum resting pressure (MRP) of IAS to increase the mucosal blood flow and promote healing. First line treatment is increasingly pharmacological. The drugs are thought to be less expensive, simpler, easily available with a good compliance, and are associated with fewer complications, requiring no hospitalization. The most frequently used drugs are nitric oxide donors, calcium channel blockers, and neurotoxins. After chemical sphincterotomy, healing rates of CAF range from 30 to 96 per cent whereas transitory minor incontinence for flatus and soiling has been reported in up to 12 per cent of patients. ${ }^{2}$ The treatment of CAF that fails medical therapy still remains unclear. Surgical treatment is generally recommended and lateral sphincterotomy seems to be the operation of

Address correspondence and reprint requests to Professor Gaetano Di Vita, M.D., Head of General Surgery, Department of Surgical and Oncologic Science, University of Palermo, via Liborio Giuffrè 5, Palermo, Italy. E-mail: divitagaetano@libero.it. choice after the failure of the conservative treatment resulting in success rates as high as 96 to 100 per cent. $^{3}$ As indicated by Nelson ${ }^{4}$ in a recent systematic review of randomized surgical trials, after sphincterotomy the overall risk of incontinence is about 10 per cent, mostly to flatus without any specification of the duration of this problem (transitory or permanent). However, it is a common belief that the risk of permanent incontinence is about 1 per cent. Nonetheless, this does not take into account the normal weakening of the sphincter with age and the possibility of future anorectal surgery, radiation, or obstetrical trauma. Therefore, the risk of incontinence after lateral internal sphincterotomy should be considered looking at the life span of the patient especially a young, otherwise healthy person. ${ }^{5}$ There is evidence that anal fissures do not always associate with hypertonic IAS; in fact CAF associated with normal or hypotonic IAS has been reported both in the elderly ${ }^{6}$ and in the postpartum period. $^{7}$ Moreover, recently, manometric studies documented that an elevated number of patients with CAF have a normal MRP. ${ }^{8-11}$ The absence of hypertonic IAS is observed more frequently in female patients ${ }^{12}$ and in the anterior CAF. ${ }^{11}$ The patients with resistant CAF without hypertonia of IAS benefit more from the 
sphincter sparing procedure than from lateral internal sphincterotomy, which may lead to incontinence.

The present study was designed to assess the efficacy of fissurectomy with advancement flap through healthy skin in healing the CAF unresponsive to medical therapy without hypertonia of IAS.

\section{Methods}

Twenty-six consecutive patients affected by CAF without hypertonia of IAS unresponsive to medical therapy and refused further medical treatment were enrolled in this prospective study from January 2002 to June 2007. All subjects gave written informed consent and the local ethics committee approved the study. Exclusion criteria were the presence of multiple and lateral fissures, chronic fistulas-in-ano, syphilis, inflammatory bowel disease, anal abscess, or malignant disease. CAF resistant to medical treatment were defined as those that fail healing after well-practiced topical medical therapy and high fiber dietary supplementation. Preoperative anorectal manometry was performed at least 4 weeks after cessation of glyceril trinitrate ointment or calcium channel blocker therapy or 15 weeks after toxin botulinum injection. A manometric control was repeated 6 months after surgery. The manometry was carried out by a manometric sensor with $2.1 \mathrm{~mm}$ external diameter with four circle orifices and with a latex microballoon at its extremity (Marquat C87, Boissy, St-Leger, France). The machine was connected to a polygraph (Narco, Byo-System MMS 200, Houston, TX) using the station pullthrough method with perfusion of normal saline; the patient was lying in the right lateral position. On the manometry, MRP was defined as maximum pressure detected on resting. Data collected by our anorectal pathophysiology laboratory, according to others, ${ }^{9}$ showed that normal range MRP values were from 45 to $85 \mathrm{~mm} \mathrm{Hg}$. CAF without hypertonia has been defined as having MRP values less than $85 \mathrm{~mm} \mathrm{Hg} .{ }^{9}$ All patients underwent fissurectomy in the gynecological position under spinal anesthesia. An Eisenhammer anal speculum was gently inserted into the anal canal, taking care to avoid sphincter dilation. After injection of $5 \mathrm{~mL}$ of local anesthetic solution, constitute of $100 \mathrm{mg}$ cloridrate mepivacain, and $0.025 \mathrm{mg}$ L-adrenaline, the fibrotic edges were excised with a scalpel until a normal nonfibrotic anodermal tissue showed sufficient bleeding. The sentinel skin tag and hypertrophied papilla at the level of dentate line, when were present, were excised. The granulation tissue at the base of the fissure was curetted until there were clean muscle fibers of the IAS. There was no use of diathermy and careful attention was given not to damage the IAS. Standard advancement anoplasty was performed using a flap of healthy skin tissue, which was mobilized and then advanced with its blood supply to fill the defect. The flap was secured without tension to the anal canal and the skin was closed tension free in a V-Y manner behind the advanced flap. All procedures were carried out by the same senior surgeon (GD). Before surgery, all patients received a small volume of phosphate-saline enema. Metronidazole was administered intravenous in a dose of $500 \mathrm{mg} 1$ hour before surgery. Subsequently, it was administered per os at the dosage of $250 \mathrm{mg}$ for 7 days three times daily. During the first 2 weeks after the operation, patients took variable doses of psyllium fiber. A laxative preparation (sennosides) was given orally to subjects who had not yet passed stools 3 days after surgery. Enema, suppositories, and all rectal manipulations were avoided. Immediately after surgery, all patients received $100 \mathrm{mg}$ of diclofenac intramuscular for analgesia and were instructed to take only $100 \mathrm{mg}$ nimesulide tablets as requested. The primary end point was fissure healing and MRP changes of the anal sphincter; the secondary end point included symptoms relief (bleeding, pain, pruritus) and the immediate and long-time complications (incontinence, anal stenosis, keyhole deformity, and urinary retention) that were recorded on pro forma. The fissure healing was defined as a complete epithelialization of the advancement flap. Both duration and intensity of pain postdefecation were evaluated. Pain intensity was scored with a visual analogical scale from 0 to 10 , where 0 corresponded to no pain and 10 to the worse pain conceivable. ${ }^{13}$ Anal incontinence was assessed 1, 6, and 12 months after the surgical operation using the Pescatori grading system: A, incontinence for flatus and mucus; B, liquid stool; C, solid stool; and 1 for occasional, 2 for weekly, and 3 for daily. ${ }^{14}$ Patients were discharged 24 to 48 hours after surgery; afterwards they were examined in ambulatory until they were completely healed and they were also checked at 1, 6, and 12 months after the surgical operation. Independently of these scheduled appointments patients were seen on request.

\section{Statistical Analysis}

Continuous variables were expressed as mean with standard deviation and qualitative data as absolute frequencies; MRP values were also given as median and range. Student's $t$ test with Welch correction was used to analyze the differences of pain score and pain duration at each registration point. Values of $P<0.05$ were considered statistically significant.

\section{Results}

\section{Baseline Characteristics of Patients}

The patients included were 23 female and 3 male with a median age of 37 years (range 18-56). Bowel 
habitus was normal in six patients, constipation was detected in 19 subjects, and diarrhea in one patient in accordance with up-dated Rome diagnostic criteria previously published. ${ }^{15}$ Seven females were nullipare, whereas nine had given birth vaginally one time or more and seven had cesarean delivery. Preoperatively, four patients reported anal incontinence. Among them, according to the Pescatori grading system, three patients were classified as A2 and one as A3.

\section{Fissure Characteristics}

The mean duration of symptoms was $19.5 \pm 9.3$ months. Six patients failed a therapeutic course of glycerin trinitrate alone. Eight patients had previously failed only botulinum toxin therapy at the dosage of 40 UI. Among the remaining 12 patients, six, after failure of glycerin trinitrate, were treated with injection of 40 UI botulinum toxin into the anal sphincter and four patients had a topically calcium channel blocker paste. The clinical characteristics of CAF are reported in Table 1. Preoperatively, the MRP values were $62.3 \pm$ $15.6 \mathrm{~mm} \mathrm{Hg}$ (mean \pm standard deviation) with a median of $65 \mathrm{~mm} \mathrm{Hg}$ and a range of 36 to $82 \mathrm{~mm} \mathrm{Hg}$.

\section{Healing Fissure and Relief of Symptoms}

All patients healed completely within 30 days from operation. The intensity and the duration of pain postdefecation was reduced significantly with respect to the preoperative values starting from the first defecation ( $P<0.0001$ and $P<0.0001$, respectively) (Fig. $1 \mathrm{~A}, \mathrm{~B})$. None of the patients complained of pain, bleeding, or pruritus 30 days after surgery. Analgesics consumption decreased significantly after the first defecation (data not shown).

\section{MRP and Anal Continence}

Preoperatively, the MRP values were a median of 60.3 $\mathrm{mm} \mathrm{Hg}$ with a range of 36 to 82. At 6 months revision, MRP values were a median of $56.8 \mathrm{~mm} \mathrm{Hg}$ with a range of 41 to 80 . Comparing the values among them, no significant difference was recorded. Preoperatively, four

TABLE 1. Clinical Characteristics

\begin{tabular}{lcc}
\hline & $\mathrm{N}$ & $\%$ \\
\hline Hypertrophied anal papillae & 21 & 80.8 \\
Skin tags & 18 & 69.2 \\
Site of fissure & & \\
$\quad$ Posterior midline & 10 & 38.5 \\
Anterior midline & 16 & 61.5 \\
Symptoms & 26 & 100 \\
$\quad$ Pain & 21 & 80.8 \\
Bleeding & 17 & 65.4 \\
$\quad$ Pruritus & & \\
\hline
\end{tabular}

patients reported anal incontinence. Among them, according to the Pescatori grading system, three subjects were classified as A2 and one as A3. One month after surgery, anal incontinence was reported in seven patients. Two patients were classified as A1, three as A2, and two as A3. At 6 months, four patients had incontinence, two of whom were classified as A1 and two as A2. At 12 months, only three patients had incontinence (Table 2).

\section{Complications and Follow-up}

One patient suffered urinary retention. There were no cases of anal stenosis or keyhole deformity. No necrosis of the transposed flap were observed. Only
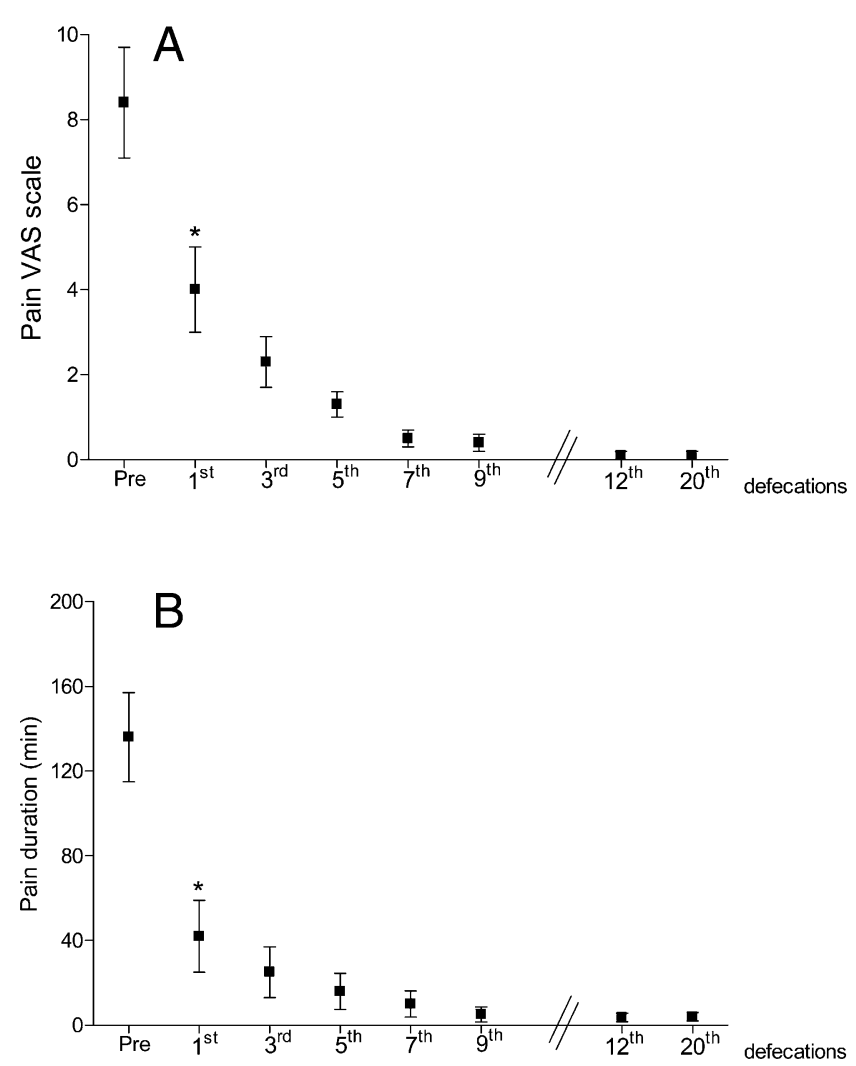

FIG. 1. (A) Intensity of pain, evaluated with visual analogue scale (VAS), given preoperatively (Pre) and at the moment of defecations. Significant differences versus preoperative values $* P<0.0001$. (B) Duration of pain, given in minutes, measured preoperatively (Pre) and at the moment of defecations. Significant differences versus preoperative values $* P<0.0001$.

TABLE 2. Anal Incontinence Assessed Before and After 1 and 6 Months from Operation According to Pescatori Grading System

\begin{tabular}{ccccc}
\hline & Preoperative & 1 Month & 6 Months & 12 Months \\
\hline 1 & A2 & A1 & - & - \\
2 & A2 & A2 & A1 & - \\
3 & A2 & A3 & A2 & A2 \\
4 & A3 & A3 & A2 & A2 \\
5 & - & A1 & - & - \\
6 & - & A2 & A1 & A1 \\
7 & - & A2 & - & - \\
\hline
\end{tabular}


complications of slight entity have been observed; in particular, two infections and a partial break down occurred in two cases. At 12 months of follow-up, no recurrences were recorded and in no cases were surgical reintervention necessary.

\section{Discussion}

This study showed that fissurectomy in combination with advancement flap associated with the excision of the sentinel skin tag and hypertrophied papilla when presents, is a safe sphincter-saving procedure for the treatment of CAF resistant to conservative treatment without hypertonia of IAS. In recent years, there has been increased recognition that some patients with CAF may have normal or low resting pressure (Table 3 ). The ability of surgeons to identify the patients with normotonic or hypotonic IAS by simple digital rectal examination is poor. ${ }^{9}$ Routine manometry of all patients with CAF may, at present, be unachievable because of the lack of both expertise and resources in every hospital. ${ }^{9}$ If manometry is used on a selective basis, it should be reserved to the patients failing topical therapy. ${ }^{9}$ Topical treatment for CAF is designed to relieve IAS hypertonia and to allow healing by improving anal blood flow. The reason why topical treatment fails could be related to the absence of IAS hypertonia. Further treatments, such as the surgical sphincterotomy, designed to obtain a lower resting pressure seem illogical; also the risk of fecal incontinence is likely to be elevated as the sphincter is already weakened. ${ }^{16}$ Chowcat et al. reported that some patients with low sphincter pressure showed a further decrease in time. ${ }^{17}$

The fissurectomy is the procedure most used to preserve the anatomo-functional integrity of the anal sphincters. Recently, Pelta et al. ${ }^{18}$ have described a subcutaneous fissurotomy that involves de-roofing a narrow subcutaneous tract found caudal to the fissure and have reported a very high success rate and a low incidence of repeated surgery. ${ }^{18}$ The fissurectomy has been associated with lateral sphincterotomy and or pharmacological ${ }^{19}$ treatment using drugs able to reduce the sphincters tone; however, the above procedures seem to be illogical in the treatment of CAF without IAS hypertonia. Fissurectomy is the excision of the anal fissure, and it can be associated with the removal of the hypertrophied anal papilla and the skin tags. Fissurectomy, as a wound debridement, removes the bradytrophic scar tissue and creates fresh wound edges, creating in essence an acute fissure. Only recently, fissurectomy alone has been used to treat CAF in adults with success, ${ }^{20,21}$ however the possible complication of keyhole defect that may lead to fecal soiling limits its use. ${ }^{22}$

The use of skin graft to cover the defect in treating CAF was first described in $1968 .^{23}$ The rationale of advancing flaps of skin and fat is based on introducing a fresh blood supply to the ischemic area of the fissure,${ }^{24}$ reducing the time of perianal wound healing, and avoiding the risk of anal stenosis that follows healing by scarring. ${ }^{22}$ Nyam et al. ${ }^{25}$ reported in 21 patients the use of a broad based V-Y advancement flap to treat CAF with normal or low MRP; in their series, all fissures healed with no flap necrosis or disturbance of continence. ${ }^{25}$ Leong and Seow-Choen in their prospective randomized trial compared the rhomboid advancement flap with the lateral sphincterotomy in 20 patients for each group. ${ }^{26}$ All fissures healed after sphincterotomy, whereas three of the 20 failed healing after treatment with advancement flap; among these, two fissures were subsequently successfully treated by sphincterotomy. ${ }^{26}$ Pescatori et al. ${ }^{27}$ observed that none of the 13 patients, who underwent a fissurectomy with anoplasty and who experienced no anal spasm at preoperative manometry, complained of incontinence or recurrence after surgery. ${ }^{27} \mathrm{Singh}$ et al. ${ }^{28}$ treated 21 patients affected by CAF resistant to topical treatment with fissurectomy and rotational flap to reduce the breakdown in the donor site. Seventeen patients had complete resolution of symptoms, only one patient continued to have severe pain, two developed a recurrent fissure, and one patient suffered from a breakdown of the flap and donor site. ${ }^{28}$ Kenefick et al. ${ }^{16}$ reported that eight patients affected by CAF that resulted unresponsive to the surgical procedure with normo or hypotonic IAS were treated successfully with the advancement flap. ${ }^{16}$ Giordano et al., in their prospective study of 51 consecutive patients with CAF, irrespective of anal tone and patient's gender, retains that advancement flap anoplasty should be considered as a first-line surgical treatment. ${ }^{29}$

TABLE 3. Data Collected from Different Studies About the Incidence of Normotonic or Hypotonic Internal Anal Sphincter in Patients with CAF

\begin{tabular}{lccccc}
\hline & Years & N of Patients & Normotonic IAS \% & Hypotonic IAS \% & Normotonic + Hypotonic \% \\
\hline Prohm and Bönner $^{10}$ & 1995 & 177 & - & - & 24 \\
${\text { Bove et al. }{ }^{11}}^{\text {Jones et al. }}$ & 2004 & 73 & 52 & 55 & 57 \\
Pascual et al. $^{8}$ & 2005 & 124 & - & - & 63 \\
\hline
\end{tabular}


In this study the fissurectomy and advancement flap in patients without hypertonia of IAS has been effective in complete healing with full resolution of the symptoms in all cases. The site for advancement was determined by the position of the CAF. Although wound infection and breakdown of the donor site are known complications of this procedure, the infectious complications and the breakdown of the donor site, that we observed, has been of a very low entity and never needed a reoperation. In conclusion, fissurectomy and advancement flap for patients with CAF without hypertonia of IAS represents a valid technique to prevent the occurrence of incontinence. In this study, only one case of temporary incontinence of low entity has been observed, in addition the severity of incontinence reported preoperatively by the patients did not show signs of worsening.

\section{REFERENCES}

1. Brugman T, Bruyninx L, Jacquet NJ. Fissure-in-ano, to divide or not to divide? Acta Chir Belg 1999;99:215-20.

2. Utzig MJ, Kroesen AJ, Buhr HJ. Concepts in pathogenesis and treatment of chronic anal fissure-a review of the literature. Am J Gastroenterol 2003;98:968-74.

3. Brown SR, Taylor A, Adam IJ, Shorthouse AJ. The management of persistent and recurrent chronic anal fissures. Colorectal Dis 2002;4:226-32.

4. Nelson R. Operative Procedure for Fissure in Ano. Cochrane Database Syst Rev 2005; Apr 18: CD002199.

5. Sileri P, Stolfi VM, Palmieri G, et al. Medical and surgical treatment of chronic anal fissure: a prospective study. J Gastrointest Surg 2007;11:1541-8.

6. Ryhammer AM, Laurberg S, Sørensen FH. Effects of age on anal function in normal women. Int J Colorectal Dis 1997;12: 225-9.

7. Corby H, Donnelly VS, O'Herlihy C, O'Connell PR. Anal canal pressures are low in women with postpartum anal fissure. $\mathrm{Br}$ J Surg 1997;84:86-8.

8. Pascual M, Pera M, Courtier R, et al. Endosonographic and manometric evaluation of internal anal sphincter in patients with chronic anal fissure and its correlation with clinical outcome after topical glyceryl trinitrate therapy. Int J Colorectal Dis 2007;22:963-7.

9. Jones OM, Ramalingam T, Lindsey I, et al. Digital rectal examination of sphincter pressures in chronic anal fissure is unreliable. Dis Colon Rectum 2005;48:349-52.

10. Prohm P, Bönner C. Is manometry essential for surgery of chronic fissure-in-ano? Dis Colon Rectum 1995;38:735-8.
11. Bove A, Balzano A, Perrotti P, et al. Different anal pressure profiles in patients with anal fissure. Tech Coloproctol 2004;8: 151-6.

12. Pascual M, Parés D, Pera M, et al. Variation in clinical, manometric and endosonographic findings in anterior chronic anal fissure: a prospective study. Dig Dis Sci 2008;53:21-6.

13. Huskisson EC. Measurement of pain. J Rheumatol 1982;9: 768-9.

14. Pescatori M, Anastasio G, Bottini C, Mentasti A. New grading and scoring for anal incontinence. Evaluation of 335 patients. Dis Colon Rectum 1992;35:482-7.

15. Thompson WG, Longstreth GF, Drossman DA, et al. Functional bowel disorders and functional abdominal pain. Gut 1999;45(Suppl 2):II43-7.

16. Kenefick NJ, Gee AS, Durdey P. Treatment of resistant anal fissure with advancement anoplasty. Colorectal Dis 2002;4:463-6.

17. Chowcat NL, Araujo JG, Boulos PB. Internal sphincterotomy for chronic anal fissure: Long term effects on anal pressure. Br J Surg 1986;73:915-6.

18. Pelta AE, Davis KG, Armstrong DN. Subcutaneous fissurotomy: a novel procedure for chronic fissure-in-ano. A review of 109 cases. Dis Colon Rectum 2007;50:1662-7.

19. Engel AF, Eijsbouts QA, Balk AG. Fissurectomy and isosorbide dinitrate for chronic fissure in ano not responding to conservative treatment. Br J Surg 2002;89:79-83.

20. Aigner F, Conrad F. Fissurectomy for treatment of chronic anal fissures. Dis Colon Rectum 2008;51:1163.

21. Meier zu Eissen J. Chronic anal fissure, therapy. Kongressbd Dtsch Ges Chir Kongr 2001;118:654-6 [in German].

22. Ayantunde AA, Debrah SA. Current concepts in anal fissures. World J Surg 2006;30:2246-60.

23. Ruiz-Moreno F. Sliding mucocutaneous flap for the treatment of anal ulcer. Dis Colon Rectum 1968;11:285-8.

24. Collins EE, Lund JN. A review of chronic anal fissure management. Tech Coloproctol 2007;11:209-23.

25. Nyam DC, Wilson RG, Stewart KJ, et al. Island advancement flaps in the management of anal fissures. Br J Surg 1995;82: 326-8.

26. Leong AF, Seow-Choen F. Lateral sphincterotomy compared with anal advancement flap for chronic anal fissure. Dis Colon Rectum 1995;38:69-71.

27. Pescatori M, Ayabaca SM, Cafaro D. Tailored sphincterotomy or fissurectomy and anoplasty? Dis Colon Rectum 2002;45:1563-4.

28. Singh M, Sharma A, Gardiner A, Duthie GS. Early results of a rotational flap to treat chronic anal fissures. Int J Colorectal Dis 2005;20:339-42.

29. Giordano P, Gravante G, Grondona P, et al. Simple cutaneous advancement flap anoplasty for resistant chronic anal fissure: a prospective study. World J Surg 2009;33:1058-63. 